\title{
MOBILE AND LOCATION-AWARE WORKPLACES AND GLOBAL VALUE NETWORKS: A STRATEGIC ROADMAP
}

\author{
Hans Schaffers \\ Telematica Instituut, hans.schaffers@telin.nl \\ Wolfgang Prinz \\ Fraunhofer FIT, wolfgang.prinz(a)fit.fraunhofer.de \\ Robert Slagter \\ Telematica Instituut, robert.slagter@telin nl \\ THE NETHERLANDS
}

\begin{abstract}
The introduction of new technologies and processes for communication, collaboration and knowledge exchange has changed considerably our work environment and the way we are organising our work. In this paper the implications of flexible mobile and collaborative workplaces for global value networks are explored through future scenarios and roadmapping. In particular we focus on the advances in mobile and location-aware workplaces and their role in organising and coordinating global business activities. The paper presents several mobile workplace scenarios and outlines a roadmap and $a$ research agenda for strategic research and innovation.
\end{abstract}

\section{INTRODUCTION}

Due to the steadily introduction of new technologies and processes for communication, collaboration and knowledge exchange, our work environment and the way we are organising our work has changed considerably over the past 20 years. In this paper we explore the implications caused by the emergence of more flexible workplaces for global value networks. In particular we are looking at the advances in mobile and location-aware workplaces and their role in the organisation and coordination of global business activities. This paper is based on findings of the MOSAIC project ${ }^{i}$, which has developed a set of generic and sector-specific scenarios, a roadmap, and a strategic research and innovation agenda for the area of mobile and collaborative workplaces.

In section 2 we are reviewing current trends towards networked organisation and networked workplaces. Section 3 presents the methodology for developing the scenarios and roadmap. The scenarios are discussed in more detail in section 4, whereas in section 5 we present the roadmap and research agenda. 


\section{NETWORKED WORKPLACES AND ORGANISATIONS}

A networked organisation can be studied from different perspectives. Whereas the top-down oriented business transactions perspective is focusing on business processes within and across its constituting organisations and their result in terms of transactions, the bottom-up perspective is that of the human worker who is a member of temporary teams and projects. Both perspectives are valuable and complementary, but result in different approaches for developing process and organisational improvements and IT support. This paper approaches the networked organisation by emphasizing the people-centric "networked workplace" and the "we-centric" services that form the core of modern workplace support.

There is empirical evidence that innovations in collaborative workplaces may further contribute to creating value and increasing productivity. Measured over a period during the $1990 \mathrm{~s}$, it appears that ICT-endowed workplace innovations account for $30 \%$ of output growth in manufacturing, and $89 \%$ of multifactor productivity (Black and Lynch, 2003). Given the productivity gap between US and Europe in exploiting ICTs, one can assume that there is a real challenge for Europe in developing more innovative workplace support. In order to realise this apparent potential, a holistic concept of workplace innovation is needed, establishing a balance between the different viewpoints and instruments: workplace organisation, IT-support, business process management. In addition cooperation and workplace design must be understood as a socio-technical process that aims at the congruency of the different viewpoints (Prinz, et.al. 1998).

From a workplace confined to particular locations and fixed working times mostly, we now are accustomed to more flexible forms of working, allowing more flexibility in choice of where and when to work. However, current collaboration and teamwork applications have changed the way we carry out tasks. This leads to a flexible workplace model enabling a diversity of new forms of team collaboration that are more independent from location and time. The flexible workplace model is enabled by information technologies which - if combined with new organisational and management processes - affect the structuring of tasks and collaboration and their dependence on context parameters in a number of ways.

- Context independence. The balance between tasks that can be carried out independent or dependent of task context parameters (time, place) is changing. Tasks increasingly can be carried out independent of time and place. In the extreme, tasks are carried out "anywhere anytime".

- Context awareness. Tasks can be carried out context-independent and contextaware. This contributes strongly to opportunities for optimizing task execution. An example is the use of location information and personal profiles for mobile salespersons, or the use of presence information for organising real-time collaboration meetings.

- Context switching. Collaboration is supported in more diverse context settings, ranging from "same time and same place" to "different time and different place" settings, and even including unpredictable places and times (Grudin, 1994).

Figure 1 categorises different types of workplace support according to the dimensions of time and place. Working in networked organisations requires the possibility to switch between different contexts and different applications. It should 
be noted that applications intended for a certain context are often unexpectedly (mis)used in other contexts. An example is the chat-like use of email for the frequent communication between local users.

Table 1: Workplace support categorisation (adapted from Grudin, 1994)

\begin{tabular}{|c|c|c|c|c|}
\hline Time & Same & $\begin{array}{l}\text { Different, } \\
\text { predictable }\end{array}$ & $\begin{array}{c}\text { Different, } \\
\text { Unpredictable }\end{array}$ & $\begin{array}{c}\text { Aware of } \\
\text { Time }\end{array}$ \\
\hline Same & $\begin{array}{l}\text { Electronic } \\
\text { meeting } \\
\text { support }\end{array}$ & $\begin{array}{l}\text { Newsgroups } \\
\text { Electronic } \\
\text { project room }\end{array}$ & $\begin{array}{l}\text { Room } \\
\text { infrastructure }\end{array}$ & $\begin{array}{l}\text { Electronic } \\
\text { project } \\
\text { meeting }\end{array}$ \\
\hline $\begin{array}{l}\text { Distributed, } \\
\text { predictable }\end{array}$ & $\begin{array}{l}\text { Video/audio- } \\
\text { conferencing; } \\
\text { Co-authoring, } \\
\text { Co-designing }\end{array}$ & $\begin{array}{l}\text { Group } \\
\text { scheduling } \\
\text { E-mail } \\
\text { Co-authoring } \\
\end{array}$ & $\begin{array}{l}\text { Shared } \\
\text { workspace } \\
\text { Virtual } \\
\text { community }\end{array}$ & $\begin{array}{l}\text { Co-authoring } \\
\text { Shared } \\
\text { workspace }\end{array}$ \\
\hline $\begin{array}{r}\text { Different, } \\
\text { unpredictable }\end{array}$ & $\begin{array}{l}\text { Presence- } \\
\text { based audio- } \\
\text { conferencing }\end{array}$ & & $\begin{array}{l}\text { Process } \\
\text { coordination }\end{array}$ & \\
\hline $\begin{array}{r}\text { Aware of } \\
\text { place }\end{array}$ & $\begin{array}{l}\text { Mobile audio- } \\
\text { Conferencing }\end{array}$ & $\begin{array}{l}\text { Presence en } \\
\text { instant } \\
\text { messaging }\end{array}$ & $\begin{array}{l}\text { Mobile } \\
\text { document } \\
\text { access }\end{array}$ & $\begin{array}{l}\text { Context } \\
\text { awareness } \\
\text { services }\end{array}$ \\
\hline
\end{tabular}

As regards current work practice, still most work is being carried out at fixed locations and fixed working times, combined with traditional forms of teleworking and working on the move as is indicated with words like "nomad" and "yo-yo" (Lilischkis, 2003). Current mobile working applications are largely limited to supporting mobile individuals such as sales representatives and managers. The element of collaboration is still lacking as it is subsumed under the practice of mobile communication. Essentially these are solutions for mobile workers, supporting mobility by enabling new and mobile forms of communication in combination with presence and location awareness information.

Mobile work can be interpreted in an even more challenging way by applying the dimension of "mobility" to work and to the workplace. Following this view, a workplace could be envisaged allowing work to be carried out anywhere and anytime. Such a concept would include the use of context information beyond location and time, enabling new forms of cooperative interaction and workspace contextualization (Schaffers, Ribak and Tschammer, 2004). This concept also emphasizes emerging new structures of collaboration. The "virtual team" consists of a project team of geographically distributed members who temporarily cooperate to accomplish a common goal. Such global virtual teams provide an opportunity whose challenges require organizational skills and sophisticated ICT support. However, the "team" as the entity of work activity, as assumed by most CSCW (Computer Supported Cooperative Work) models, may decrease in importance giving rise to socalled 'intensional networks" (Nardi, Whittaker and Schwarz, 2002). In such a way, mobile and location-aware technologies together with broadband networks and groupware applications and embedded in new collaborative structures and processes provide much scope for exploiting the potential of decreasing cost of 
communication in enabling new forms of decentralization and networked organizations (Malone, 2004).

\section{SCENARIO METHODOLOGY}

Our approach to arrive at scenarios and roadmaps followed stages of vision development, analysis of current practice, trends and future scenarios, identification of gaps and challenges, development of a strategy for workplace innovation, and proposing a roadmap for research and technology development. The work was validated in workshops. We discuss some of these steps in more detail.

In order to explore the strategic research and innovation issues, we started with confronting current mobile working practice with a more future-oriented mobile workplace vision in order to explore the diversity of aspects in mobile work and workplace mobility. Three types of current workplaces were distinguished in terms of mobility support and work location changes (Figure 1): micro-mobility: supporting on-site mobility; multi-mobility: supporting ad-hoc and occasional mobility; and total mobility: supporting on the move working.

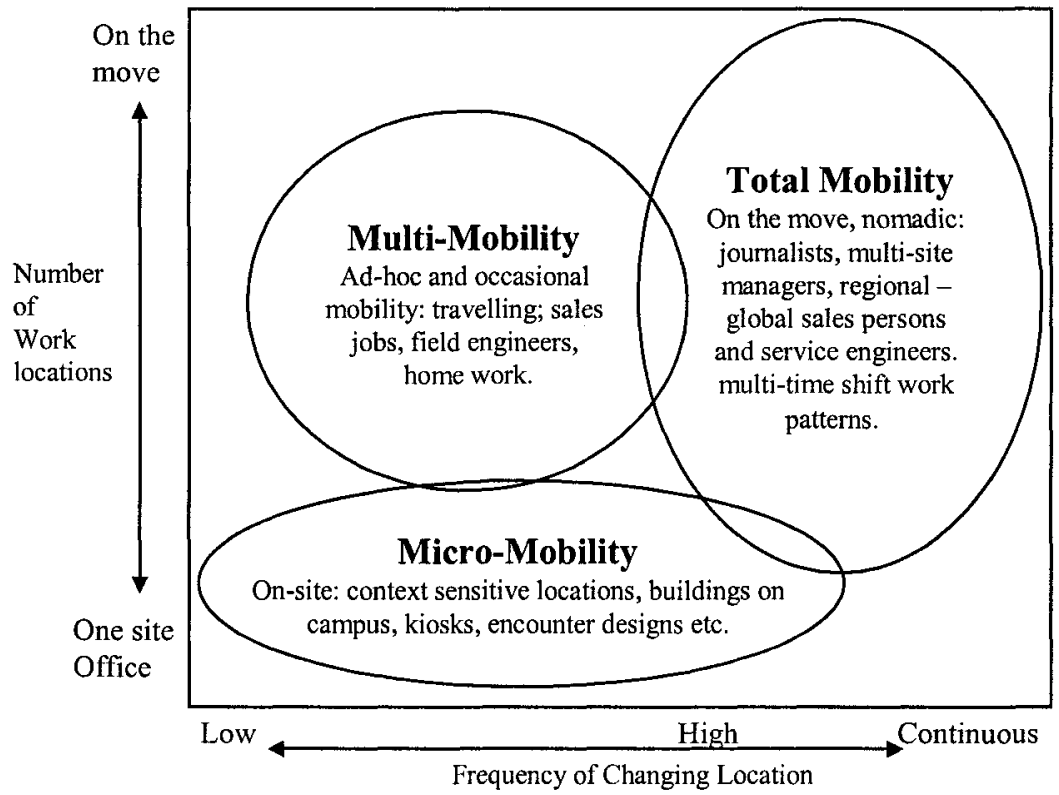

Figure 1: Mobile workplaces categorisation (Schaffers et al, 2005a)

The vision of "mobile and networked workplaces", emphasizing the concept of anywhere and anytime context-aware working, took its point of departure in the formulation of a strategy for workplace innovation at the European level. It was understood that modernisation of the work environment could contribute considerably to the objectives of growth, productivity and innovation. As the next step, the mobile workplace vision was made more concrete by developing a scenario framework of underlying driving forces. 
Major forces driving future workplace designs were assumed to include technological transformation, globalisation and competition, demographic change, management style, European enlargement, and work-life balance needs. Two uncertain driving forces affecting future ways of working, "human identity" and "organisational development" were selected as key factors. This results into a scenario framework of distinct environments of future mobile and collaborative workplaces. The framework then was used to identify and analyse six different scenarios. These scenarios were conceived as strategies to cope with, and explore, the environments. Storylines were formulated and key aspects of the scenarios were assessed such as success factors and technology, behaviour, and organisational and societal requirements and challenges. Figure 2 depicts the scenarios.

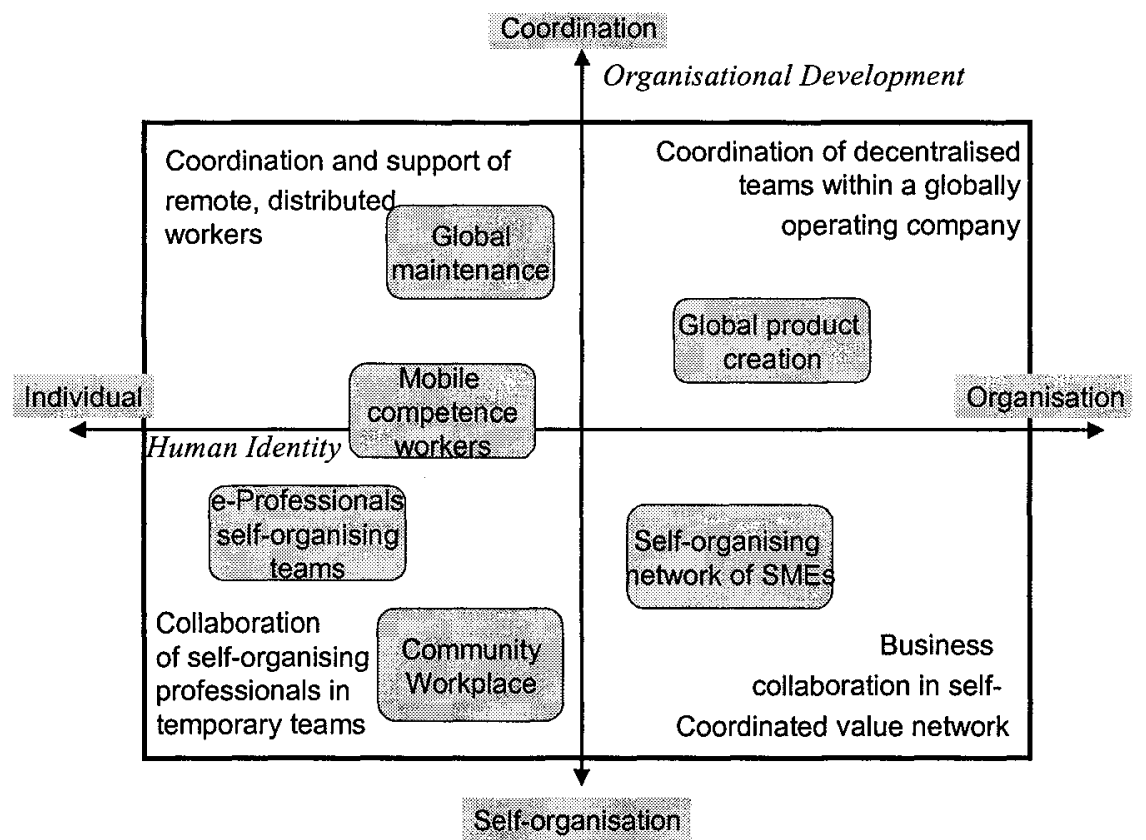

Figure 2: Workplace scenario driving forces framework (Schaffers et al, 2005a)

The objective of these scenarios is to challenge existing frames of mind in envisaging different types of workplaces than those already existing and to show plausible future directions for innovation. They highlight underlying forces and uncertainties, and enable us to anticipate change and to widen decision options. They are not meant to present business opportunities, but of course could embed such opportunities. In order to link the scenario process to the identification of new business opportunities, two levels of scenario development were distinguished. Apart from the generic scenarios, specific scenarios and deployment strategies for mobile workplaces have been developed for different sector domains such as aerospace, automotive, health, and building and construction as well as for working in rural and regional areas. 


\section{MOBILE WORKPLACE SCENARIOS}

In focusing on the role of networked workplaces in global value networks, we present three scenarios of Figure 2, highlighting various aspects of the framework Schaffers et al. 2005b).

\section{Scenario 1: Global product creation in a networked company}

This scenario describes a global product creation environment of a company that has operations in several sites in different countries and in various time zones as well. Most of the product creation processes involve several partners, subcontractors and client sites in different countries. The company exploits a network of co-located sites in different time zones that optimally utilizes the available competencies of each different site. This requires effectively mobilizing both the work (tasks) and the worker, and has direct implications for work processes and the work environment needed to increase productivity. The rationale behind this scenario is the evolving global division of work and increasing speed of innovation and productivity requirements.

The scenario identifies three different patterns of mobility: the Mobile, Campus based and Desk-based worker. The Mobile worker typically works between many locations. He owns no dedicated workspace, needs remote access to most of his resources and may work from home for up to 2 days a week. The Campus mobile worker typically works in one location but is highly mobile and away from his desk for considerable amounts of time. This requires solutions for managing storage and personal material. The Desk-based worker uses a dedicated team workspace in a company location. Resources should be office based but preferably, desks should be cleared and made available to others when they are out. The technologies needed to support this scenario relate to hot-desking, context sensitive locations, instant privacy technologies, 'follow-me' printing services, security, authentication, interoperability issues and multi-access wireless technologies. The work tasks can be addressed by using multi-shift work patterns. This is also an area where exploitation of work mobility instead of worker mobility brings highest value and therefore different virtual workspace arrangements are common.

\section{Scenario 2: Mobile competence workers in global supply chains}

This scenario reflects ongoing trends in individual working habits of competence workers and in organizational structures of globally operating companies: the trend to mobile teleworking and mixed forms of teleworking; to more autonomy in the individual organization of working time and location; to blending in professional and private spheres; to more dynamic and flexible organizational structures and globalization with semi-autonomous decentralized bodies of subsidiaries.

The scenario shows how mobile technology can both improve work in a globally operating supply chain and how it can make life easier for competence workers. The work of a lead buyer of a globally operated and distributed trading company is described. The company is hierarchically structured with (almost) autonomous subsidiary companies in many countries throughout the world and in many time zones and languages, down to the actual markets for end customers. Purchasing is handled by decentralized purchase companies, one for each country, sometimes even for regions. The lead buyer works in a central purchasing unit and is responsible for 
strategic purchasing between the regional purchasing companies. She works in the central headquarters, but frequently has to travel around to coordinate purchasing with regional purchase managers in various countries or to negotiate with suppliers. Her work is characterized by a dependency on inhouse databases and information systems as well as a high degree of informal communication and document exchange with internal staff and external suppliers. The lead buyer frequently works at home or at other premises.

ICT in the company consists of standard inhouse applications which are networked (database systems, document management system, etc.). Security is an important issue, considering the amount of industrial espionage world-wide. The ICT system is quite regulated with a high degree of networking, but between subsidiaries, there is mainly informal communication and unstructured exchange of documents.

The scenario reflects a trend to more dynamic and flexible workplace organizational structures. Other trends focus on mixed forms of teleworking (as opposed to sedentary telework at home), more autonomy for the individual in the work organisation, excellent security for ubiquitous access to data and the blending of professional and private spheres. The scenario also identifies globally networked companies consisting of decentralized subsidiaries and support for an international multi-cultural workforce.

\section{Scenario 3: Self-organising network of SMEs}

This scenario represents the situation of SME managers collaborating in a selfcoordinated network in order to jointly pursue business opportunities in design and manufacturing. The network expands internationally taking up new members and establishing local presence, and adding new services such as maintenance.

Whereas globalisation and outsourcing threaten the position of local suppliers, at the same time these forces provide new opportunities to participate in global supply chains. Research, design and production is migrating throughout the world, following local markets and enforcing optimization of supply chains. ICT and organisational innovations help SME suppliers to adapt to these forces enabling them to become part of international value systems. Collaborative workplaces and mobile working enable them to strengthen teamwork more independently of place.

Our SME initially collaborates within a regional SME network to jointly market products and share resources in design, accounting and marketing. Its members are independent and contribute to managing the network. An electronic market passes requests for supplies, and a collaboration platform is used to discuss project participation and sharing of resources. The network selects partners for collaboration with the contractor, using shared workspaces. New partners can be selected and negotiations supported. A design company in the network sets up design team and works with customer real-time and non-real time. The network gradually expands its international presence, allowing international partners to participate in the network. The network uses mobility support to enable communication and collaboration at varying places and times, access to documents and experts when needed.

Requirements and challenges to be met to make the scenario happen are many. Among them: business models for networked collaboration; new processes and tools for project oriented collaboration; integration of personal network presence and calendar functions into the network; near-life remote meeting support; competence 
and experience profiling of partners; trust and security management; collaboration between remote units and people; workspaces for co-design, co-engineering, project preparation and management; and supporting multi-dimensional work contexts such as working simultaneously for different companies.

\section{ROADMAP AND STRATEGIC RESEARCH AGENDA}

The scenarios learn us several lessons enabling us to sketch a plausible development path for future mobile and collaborative workplaces. To a large part, economic factors affecting mobility such as cost of transportation and ICT affect the future workplace. Technology factors such as the migration towards all-IP networks and the large-scale adoption of mobile technologies can also be considered as relatively certain trends. These trends are part of all scenarios. More interesting is the role of the uncertain factors that drive future ways of working. The scenarios are outcomes under a "what-if" question: what if individualism will grow, and organizations will tend to become more self-organising? What will be the problems and opportunities in that situation, and what are the instruments available? Such questions allow us to consider success and failure factors and situation-dependent strategies, even if such "if' situations will not be realised. In our opinion the most important lessons conveyed by the scenarios can be summarized as follows:

- Global division of work will be a major development, but work-life balance issues could hinder its full development and undermine current social models.

- Mobile workplaces can support the globalisation of supply chains, but require new forms of leadership, coordination and management.

- E-professionals in a self-organising community are a promising model, but will require new business models and legal arrangements.

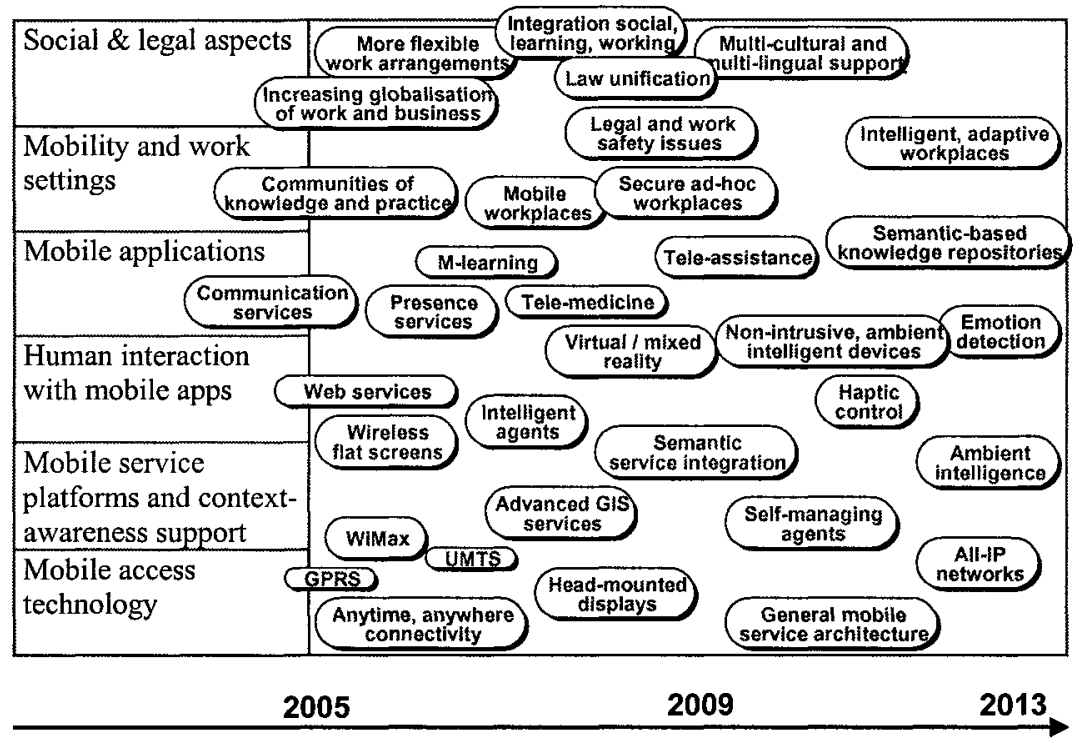

Figure 3: Initial roadmap for mobile work (Slagter and Schaffers et al, 2005) Table 2: Mobile workplaces 2005 - 2013 (Slagter and Schaffers et al, 2005) 
$2005-2006$

- Widespread use of combinations of PDA/mobile phone; mainly e-mail use; first mobile blogging approaches

- Emphasis on limited forms of micro-mobility: on-site mobile working at context sensitive locations, kiosks, encounter designs etc

- Standard groupware tools become more adapted to mobile settings

- Context-sensitivity covers mainly location and time parameters

- Emphasis on ad-hoc and occasional mobility: buildings on campus, traveling, sales jobs, field engineers, home work

- Connectivity sufficient for document sharing and IP-based audio conferencing

- Research on "workspace authoring" enabling on-demand workspace support for adhoc mobile teams

\section{$2007-2008$}

- Location-based personal services become dominant: where is my daughter?

- Mobile community and content services; community based organisation structures

- Complex forms of context sensitivity and better multi-user interfaces are realized, supporting mobile ad-hoc project teams

- Increase of well-supported forms of micro-mobility and multi-mobility; decrease of forms of total mobility

- Increasing support of mobile teamwork in engineering, maintenance, services industries; including solutions for mobile workplace knowledge access/ sharing

- Pilots in on-demand mobile workplace support tools

- Resistance to changing workplace settings is developing; is addressed by paying more attention to policies for workplace health and safety

\section{$2009-2013$}

- Mobile phones migrate into clothes and other devices

- Elementary forms of networked, "ambient" workplaces become reality with seamless transition between diversity of workplace styles

- Applications of mobile working in globally dispersed engineering and service teams and in collaborative learning

- New forms of networked organization, enabling high level of interaction between central and decentralised levels and accommodating flexible forms of mobile working become reality and are becoming part of EU business infrastructure

- Negative impacts of workplace innovations on family conflict and work-life balance are not resolved, could create new divides

These aspects lead us to revisit the mobile workplace vision and develop a more concrete strategy for mobile workplace innovation and agenda for research. In Table 2 we propose a set of "stages" for mobile workplace evolution for the next decade. These stages represent advances including technical, social, behavioral and policyrelated factors. These stages form the basis for a roadmap of technical and nontechnical innovations represented in the roadmap in Figure 3. To structure this roadmap for collaborative mobile workplaces we have analyzed the emerging development pattern based on the following six RTD (Research Training and Development) and innovation areas: (1) Social and legal aspects; (2) Developments in mobility and work settings; (3) Implications for and developments in mobile applications; (4) Human interaction with mobile applications; (5) Mobile service design and service platforms; (6) Mobile access technology. In a next step these developments were positioned on a time-scale. The high-level roadmap shows the 
key challenges and milestones for realising mobile and collaborative work innovations.

Systemic innovation requires a multidisciplinary approach to joint RTD in Europe. Based on the MOSAIC scenarios and development pattern as well as on the scenarios of the Collaborative Work Experts Group ${ }^{\text {if }}$ we have identified key issues for joint RTD as summarized in the following as research clusters.

\section{1) Business models for a networked and mobile society}

The new opportunities and demands of mobile work require the development of new business models that reflect the change from application to service driven solutions. Workers will no longer work and cooperate with or through an application, but they will use a mobile collaboration service. Thus people will not focus in the procurement of devices or software but on the on demand use and payment of context available services.

\section{2) Design and tailoring methods for mobile workplaces to address individual demand and needs for end-user tailoring}

Local workplaces are often designed due to the organisational or group requirements and guidelines. However, mobile workplaces are more specific to the individual or the cooperating community. Therefore methods are needed that address the balance between the self-organisation of mobile and local work as well as the integration into the organisational procedures. This will lead to the development of community based workplaces vs. organisational departments, requiring flexible access to shared workspaces, from strictly private to publicly accessible.

\section{3) Trust and security management in a mobile world}

Big challenges for flexible, mobile and local cooperation are security issues. Security threats make it more and more difficult to establish ad hoc cooperation spaces between arbitrary partners. Organisations are very reluctant to open their cooperation environment to others. Thus users are often forced to use third party services for inter-organisational cooperation. This leads to inconsistencies and problems in intra- and inter-organisational cooperation due to inhomogeneous applications and systems. To overcome this problem we need new approaches to an easy to use and end-user configurable security management for inter-organisational community based cooperation.

\section{4) Sharing multi-dimensional work contexts and telepresence}

Community based and mobile workplace cooperation includes multi-dimensional work contexts such as working simultaneously for different companies, including their systems, processes, rules, cultures. This requires methods for easy switching between workspaces. This can be on a horizontal level: for co-design, coengineering, project preparation and management; or on vertical levels: coordination of business processes at different levels (global data collection, local diagnostic centres, maintenance engineer). A particular demand derived from that is the need for awareness mechanisms that enable user to stay on top of their work processes and contexts.

\section{5) Models for coordinating business work processes for mobile users}

The coordination of business processes at different levels (global data collection, 
local diagnostic centres, maintenance engineer) integrating mobile users and processes requires new models to reflect the context (location, availability, service availability, etc.) of the users.

6) Tools and services enabling end-user configuration of community based workplaces in a mobile world

Beyond current services for shared workspaces we need tools for end-user creation of ad-hoc workspaces including services for ad-hoc contextualised collaboration as well as for finding people and knowledge.

7) Standardizing ubiquitous access to mobile workplaces and ambient intelligence environments: reference models for mobile workplaces and ambient environments

Mobile work in different environments demands ubiquitous access to Internet and to devices such as touch sensitive screens, keyboards and pens. This can be achieved only if standards exist. A prerequisite for this is the development of reference models for mobile workplaces and ambient environments that reflect adaptiveness, scalability and interoperability.

8) Field test for integrating the next generation mobile devices into real business

Special application domains must be identified to perform field tests or living labs in which the technologies as well as the impacts are investigated and understood.

\section{9) Social impact of distributed working relations}

The impact of mobile and distributed working relations in knowledge communities is not yet fully understood. Further research must be performed to understand the risks and opportunities and to develop methods for adequate training or tools (presence, awareness tools) that can support the transformation to these new work styles.

\section{0) Adapting home and business environment}

Mobile work involves working at different places including the home environment. This goes hand in hand with blurring the border between business and private life. As a consequence technologies are needed to adapt and to integrate the home and business environment as well as to find business and working models that support the integration of business and private life.

\section{CONCLUSIONS}

This paper contributes a scenario-based approach for the development of a roadmap and a research agenda for mobile and location-aware workplaces. Based on the identification of scenarios that represent different driving forces for future work situations, a roadmap has been presented that covers both ICT as well as social and organizational factors. Among the different research issues that have been identified we consider as the most important: design methods for mobile workplaces to address individual demand and needs for end-user tailoring such that a satisfactory work-life 
balance can be established. To overcome the increasing complexity of todays workprocess easy methods for sharing multi-dimensional work contexts and task are needed. This must be combined with the development of tools that enable the enduser configuration of community-based workplaces to enable users to tailor their workplaces to the needs of the work task and processes instead of organizational constraints. Perhaps the most important but also most problematic issues is the standardizing of ambient intelligence environments to achieve reference models for mobile workplaces. Only such an effort can guarantee a local and global interplay. We hope that the thoughts presented in this paper can guide such a process.

\section{ACKNOWLEDGMENTS}

The work has partly been funded by the European Commission through the MOSAIC Specific Support Action (FP6-2003-IST-2). The authors express their gratitude and appreciation to MOSAIC project partners for their contributions to scenario building and roadmap construction. In particular we acknowledge VeliPekka Niitamo, Elke Hinrichs, Marc Pallot and Seamus Hickey for contributing to scenario development.

\section{REFERENCES}

1. Black SE, Lynch LM. What's driving the new economy? The benefits of workplace innovation. FRBSF Working paper 2003-23, 2003.

2. Grudin J. Computer-Supported Cooperative Work: Its History and Participation. IEEE Computer, 27, 5, pp 19-26, 1994.

3. Lilischkis S. More Yo-yos, Pendulums and Nomads: Trends of Mobile and Multi-Location Work in the Information Society. STAR Project Issue report Nr. 36, Empirica, Bonn, 2003.

4. Malone TW. The Future of Work. Harvard Business School Press, 2004.

5. Nardi B, Whittaker S, Schwarz, H. NetWORKers and their activity in intensional networks. Journal of Computer-supported Cooperative Work, Vol 11, Issue 1-2, pp205-242, 2002.

6. Prinz W, Mark G, Pankoke-Babatz U. Designing Groupware for Congruency in Use. In Proceedings '98: ACM Conference on Computer Supported Cooperative Work, Seattle, ACM Press, pp373$382,1998$.

7. Schaffers H, Ribak A, Tschammer V. COCONET: A Roadmap for Context-Aware Cooperation Environments. In Processes and Foundations for Virtual Organizations, L.M. Camarinha-Matos and H. Afsarmanesh (eds), Kluwer Academic Publishers, pp47-64, 2004.

8. Schaffers H (ed), Carver L, Fernando T, Hickey S, Hinrichs E, Martland D, Niitamo VP, Pallot M, Prinz W, Vollmer S. Mobile working: vision, scenarios, challenges. MOSAIC FP6-2003-IST-2 Project Report D1.1 (Draft), 2005a.

9. Schaffers H (ed), Hickey S, Hinrichs E, Niitamo VP, Pallot M. The MOSAIC Mobile Workplace Scenarios. MOSAIC FP6-2003-IST-2 Project Report D1.1.2 (Draft), 2005b.

10. Slagter R and Schaffers H (Eds.), Brugnoli C, Hickey S, Lorusso I, Niitamo VP, Pallot M, Prinz W, Pulli P, Rissanen M, Tarchalska A, Turowiec A. Mobile workplaces roadmap report. MOSAIC FP6-2003-IST-2 Project Report D1.2 (Draft), 2005.

\footnotetext{
${ }^{i}$ MOSAIC is a Specific Support Action in the IST priority of the $6^{\text {th }}$ Framework Programme of the European Commission, running 2004-2005. See: http://www mosaic-network.org/.

ii $\mathrm{http}$ //europa.eu.int/information_society/activities/atwork/work_paradigms/experts_group/index_en.htm
} 